Research Article

\title{
The mediating role of self-compassion in the relationship between perfectionism and academic procrastination in pre-service teachers
}

\author{
Ahmet Sapanc1 \\ Düzce University, Turkey
}

\begin{abstract}
The aim of this study is to examine the mediating role of self-compassion in the relationship between perfectionism and academic procrastination in teacher candidates. Structural equation modeling, one of the quantitative research methods, was used in the study. The participants of the study consisted of a total of 478 teacher candidates, 328 female and 150 male, between the ages of 18-41. Personal Information Form, Aitken Procrastination Inventory, Frost Multidimensional Perfectionism Scale and Self-Compassion Scale were used as data collection tools in the research. According to the findings, perfectionism has a negative relationship with self-compassion, perfectionism has a positive relationship with academic procrastination, and self-compassion has a negative relationship with academic procrastination. As a result of the Bootstrap analysis for the significance of indirect effects, it was found that self-compassion had a partial mediating role in the relationship between perfectionism and academic procrastination.
\end{abstract}

Keywords: Self-compassion; Perfectionism; Academic procrastination; Pre-service teachers

Article History: Submitted 23 May 2021; Revised 1 December 2021; Published online 31 December 2021

\section{Introduction}

\subsection{Academic Procrastination}

Aside from common responsibilities such as taking care of household chores, paying bills, and caring for people in daily life, individuals have a variety of responsibilities that range from participating in project work to writing an article. However, the individual may not always do all of these tasks or may postpone some of them. Procrastination is a common self-regulatory problem that involves delaying or failing to complete crucial tasks, despite the fact that knowing it has negative consequences (Lay, 1986; Sirois \& Pychyl, 2013). Procrastination can occur only in certain contexts such as academic life, or it can be a relatively permanent personality trait that manifests itself in various aspects of life (Sirois, 2016a).

As a type of procrastination, academic procrastination involves delaying duties and activities related to learning and work. According to studies on academic procrastination, procrastination

Address of Corresponding Author

Ahmet Sapanc1, PhD, Düzce University, Faculty of Education, Guidance and Psychological Counseling Department, 81620, Düzce, Turkey.

$\bigotimes$ ahmetsapanci@duzce.edu.tr

0000-0003-4688-6890

How to cite: Sapanc1, A. (2021). The mediating role of self-compassion in the relationship between perfectionism and academic procrastination in pre-service teachers. Journal of Pedagogical Research, 5(4), 214-229. https:// doi.org/10.33902/JPR.2021474638 
tendencies of the students increased steadily throughout their university careers, with the lowest rates in the first grades and the highest in the last grades (Semb et al. 1979 as cited in Solomon \& Rothblum, 1984).

In a study on the frequency of academic procrastination, Solomon and Rothblum (1984) reported that $46 \%$ of their students postponed writing term papers, $27.6 \%$ procrastinating their studying for exams, and $30.1 \%$ do weekly homework. In addition, $23.7 \%$ of the students stated that they thought that the procrastination behavior they experience while preparing term papers, $21.2 \%$ while studying for exams and $23.7 \%$ while doing their weekly homework was a major problem for them. Another significant finding of the study was that $65 \%$ of students stated that they were unhappy with procrastination behavior when writing term papers, $62.2 \%$ when studying for examinations, and $55.1 \%$ when doing weekly assignments and desired to eliminate it (Solomon \& Rothblum, 1984).

Academic procrastination occurs when a person actively postpones a study-related action plan, even though he or she expects the delay to be worse (Steel \& Klingsieck, 2016). This delay will, without a doubt, have a variety of implications. The popular belief that academic procrastination has negative effects for students' academic progress and subjective well-being is supported by studies on academic procrastination and its implications. There are many studies showing a relationship between academic procrastination and low student grades (Beswick et al., 1988; Fritzsche et al., 2003; Klassen et al., 2008; Moon \& Illingworth, 2005; Steel et al., 2001; Tice \& Baumeister, 1997; van Eerde, 2003). Academic procrastination also affects the health of the individual negatively, causing mental and physical stress, sleep-related problems, fatigue and illness (Grunschel et al., 2013a; Patrzek et al., 2012; Rothblum et al., 1986; Tice \& Baumeister, 1997). Procrastination also has negative emotional consequences such as anxiety, anger, shame, dissatisfaction, sadness, feeling under pressure, and guilt (Grunschel et al., 2013a; Patrzek et al., 2012; Pychyl et al., 2000; Rothblum et al., 1986; Tice \& Baumeister, 1997). In addition to these negative consequences of procrastination, students stated that they had problems in their private lives, such as negative reactions from others, financial costs, and interference with their career plans, and these problems spread to the academic field as well (Grunschel et al., 2013a; Patrzek et al., 2012 as cited in Steel \& Klingsieck, 2016). Academic procrastination is a common problem that negatively affects both academic and private lives of university students and causes significant performance losses. In this context, determining the factors associated with academic procrastination constitutes an important step in the process of reducing and preventing the problem. When the variables related to academic procrastination are examined, it is seen that perfectionism can play a triggering role in procrastination behavior. As a matter of fact, the findings in the related literature such as procrastinators have more perfectionism characteristics than non-procrastinators (Ferrari, 1992), there is a positive relationship between academic procrastination and three sub-dimensions of the Multidimensional Perfectionism Scale, which are mistakes and doubts, parental expectations and criticism, and personal standards (Jadidi et al., 2011), individuals with dysfunctional perfectionism set high standards that are difficult to meet, and therefore they tend to delay starting the task by delaying it (Shafran \& Mansell, 2001) support this connection. In this context, perfectionism seems to play an important role in understanding academic procrastination.

\subsection{Perfectionism}

Setting unrealistic criteria for one's performance and being unable to bear the prospect of failing to meet these standards is known as perfectionism (Frost et al., 1990). Individuals with a high level of perfectionism take an overly critical attitude towards themselves when they cannot reach the high standards they set. Perfectionism, which is generally accepted as a "common neurotic style" that includes feelings of failure, guilt, shame, and low self-esteem, is a structure consisting of individual and social characteristics that harm both the psychological adjustment and general well-being of individuals (Hewitt \& Flett, 1991). 
Burns (1980) defines perfectionists as people who set unrealistic standards and constantly push the conditions to reach these goals, and who measure their own values in terms of productivity and success. The reason for these self-imposed demands for personal standards is explained by the fact that they are motivated by fear of failure rather than a desire for improvement (Burns, 1980).

In the relevant literature, perfectionism is recognized as a multidimensional structure with adaptive and maladaptive aspects (Hamachek, 1978; Frost et al., 1990; Hewitt \& Flett, 1991; Stoeber \& Gaudreau, 2017). Various researchers examining this multidimensional structure of perfectionism have stated that the different forms and sub-dimensions of the concept can actually be grouped into two superordinate factors, perfectionist efforts and perfectionist concerns (Frost et al., 1993; Stoeber \& Otto, 2006; see also Cox et al., 2002; Dunkley et al., 2000 as cited in Stoeber and Gaudreau, 2017). In this conceptualization, perfectionist efforts constitute adaptive perfectionism, and perfectionist concerns constitute maladaptive perfectionism.

According to Hamachek (1978), who has researched different forms of perfectionism, the main difference between normal and neurotic perfectionists is that normal perfectionists have greater latitude to allow minor imperfections in their performance and still consider themselves successful. Neurotic perfectionists are so concerned with mistakes that even small mistakes can lead to the perception that their standards are not being met. According to Burka and Yuen (2008), maladaptive perfectionists worry excessively about making mistakes. The champion athlete, highly successful businessman and Nobel laureate scientist also knows that he can make mistakes, have a bad day, sometimes his performance can drop temporarily, and he can tolerate the disappointments he will experience for this. In contrast, maladaptive perfectionists have unrealistic expectations of themselves. For example, a person who has not exercised for years wants to be in top physical condition within two weeks. A first-time novelist wants their first draft to be of publishable quality. As a result, high standards that aim to motivate people for success often become impossible standards that hinder their efforts (Burka \& Yuen, 2008).

In the light of the information presented above, it is seen that perfectionism plays a role in triggering procrastination behavior. As the level of perfectionism rises, individuals set higher success standards for themselves and tend to procrastinate in order not to face the feeling of failure that will result from not reaching these standards. The negative effects of procrastination on academic achievement, social relations, physical and mental health cause the person to approach himself more self-judgmentally and negatively. In overcoming this vicious circle, it is important for the individual to adopt a more understanding attitude towards himself and an accepting attitude in the face of failures. In this context, self-compassion can play a critical role in explaining the relationship between perfectionism and academic procrastination. In this sense, it is expected perfectionism is related lower levels of self-compassion, which in turn leads to higher levels of academic procrastination

\subsection{Self-Compassion}

The concept of self-compassion, which takes its basis from Buddhist philosophy and emphasizes that one should be loving and compassionate towards oneself, is the desire to accept their pain and heal it with compassion instead of escaping or cutting off relations with them (Neff, 2003a). Selfcompassion involves taking an understanding approach to oneself without being critical and judgmental towards one's own failures, mistakes, or inadequacies. With this approach, the person can accurately see their problems, weaknesses, and shortcomings, and can respond to these negativities with compassion and kindness rather than self-criticism and harshness. In this way, self-compassion can be negatively related to negative events and cause positive emotions when life goes bad (Leary et al., 2007).

The concept of self-compassion, operationally defined by Neff (2003b), consists of three basic components: self-kindness, common humanity, and mindfulness. Self-kindness is when an individual approaches himself with an understanding, accepting and compassionate attitude, tries to understand himself without prejudice, and adopts a gentle and loving attitude towards himself 
instead of judging and criticizing himself harshly (self-judgment). Being kind, compassionate and understanding towards oneself instead of criticizing oneself includes showing forgiveness, empathy, sensitivity, warmth, and patience towards oneself, including all of one's actions, feelings, thoughts and impulses (Gilbert \& Irons, 2005; Neff, 2003a). The self-compassionate person acknowledges that he deserves love, happiness, and compassion, even after failure. The person who chooses to judge himself instead of having self-compassion engages in acts of hostility, humiliation, and negative self-criticism (Neff, 2011). People who judge themselves tend not to accept their own feelings, thoughts, impulses, actions, and values (Brown, 1998).

The second component of self-compassion, the dimension of common humanity, is accepting that the suffering is shared and being aware that it is shared by all humanity. Individuals with such awareness see these experiences as a part of broad human experiences rather than experiencing feelings of social alienation and isolation in the face of failure, painful and distressing experiences. Mindfullness, which is the third component of self-compassion, is a state of awareness that keeps emotions and thoughts in a balanced awareness in the face of painful experiences and does not allow the individual to be dragged by the emotions he/she experiences. Self-compassion causes the person to approach their negative experiences in a balanced way, so that painful emotions are neither suppressed nor exaggerated (Neff et al., 2007). At the same time, mindfulness requires that we "not overidentify" with thoughts and feelings so that we are carried away by negative reactions. Mindfulness involves awareness, attention, and acceptance of the present moment, in the phenomenon of having mindful awareness rather than avoiding or overidentifying with one's painful thoughts and feelings (Shapiro et al., 2005).

Self-compassion is a healthy coping method that individuals can use in the face of negative situations (Neff, 2003a). For this reason, it is thought that individuals' having understanding and sensitivity both for others and for themselves can help them to evaluate and leave behind the events in a healthy way and to protect their mental health. When the literature is examined, there are many studies showing that self-compassion was positively related to many variables that affect mental health positively, and negatively related to variables that affect it negatively and some psychological disorders. In studies on psychopathology, it is seen that self-compassion is mostly studied together with depression and anxiety and had a negative relationship with these disorders (Neff, 2003a; Neff et al., 2005; Neff et al., 2007; Raes, 2010; Ying, 2009). In a meta-analysis study conducted by MacBeth and Gumley (2012), examination of 14 different studies on self-compassion and mental health using the Self-Compassion Scale developed by Neff (2003b) revealed that high self-compassion was associated with low psychological symptoms. In a study by Einabad et al. (2017), it was found that self-judgment and over-identification, which are sub-dimensions of selfcompassion, have full mediator role in the relationship between anxiety and procrastination.

When the information presented above in relation to the relevant literature is evaluated in general, it is seen that academic procrastination is a variable that produces serious negative results in many areas for university students. Therefore, determining the variables associated with procrastination is an important step in the preparation of the necessary intervention plans. In this context, perfectionism stands out as an important predictor of academic procrastination. When the previous studies on the subject were examined, it was seen that there were very few studies in which the direct relations between perfectionism and procrastination were investigated, mediating variables were examined, and indirect relations were tested. No study has been found that examines the mediating role of self-compassion in the relationship between perfectionism and procrastination. In this sense, it is thought that the present study will make an important contribution to the relevant literature on the explanation of the indirect relationships between the variables and the mediating role of self-compassion in this process.

Because of the overwhelming focus on success when discussing self-worth in an academic setting, perfectionist students may develop a fear of failure that promotes academic procrastination. Academic procrastination can serve as a shield against the fear of failure in this situation. Thus, academic procrastination works as an ego defense mechanism and can often be 
used as a protective tool by those with fragile self-esteem (Burka \& Yuen, 2008). This study aimed to examine the mediating role of self-compassion, which refers to individual's approach with a self-accepting attitude. Therefore, higher levels of perfectionism would be related to lower levels of self-compassion, which in turn related to higher levels of academic procrastination. It is thought that the findings obtained in the research will contribute to both educators and mental health workers in the process of developing preventive and intervention programs.

\section{Method}

\subsection{Research Design}

In this study, structural equation modeling was used to determine the mediating role of selfcompassion in the relationship between perfectionism and academic procrastination in teacher candidates. The conceptual model tested in the research is shown in Figure 1.

Figure 1

Hypothetical Model

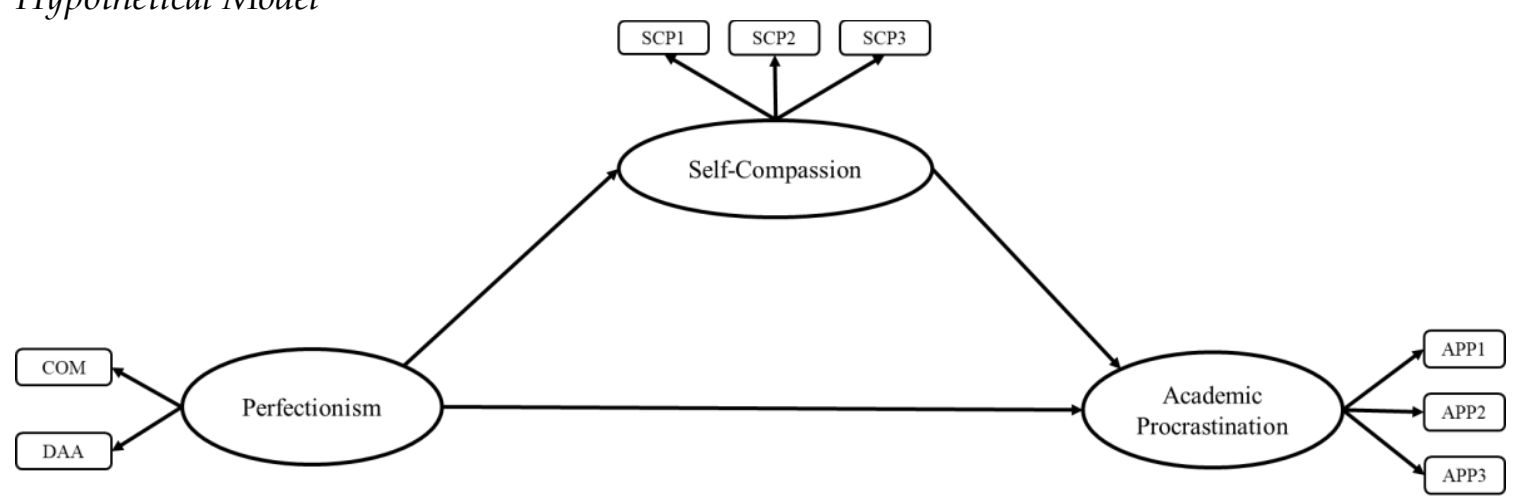

COM: Frost Multidimensional Perfectionism Scale Concern Over Mistakes subscale total score, DAA: Frost Multidimensional Perfectionism Scale Doubts About Actions subscale total score, SCP1-3: Three parcels from SelfCompassion Scale items, APP1-3: Three parcels from Aitken Procrastination Inventory items

\subsection{Participants}

Convenience sampling method was used while determining the participants of the study. According to gender, $68.6 \%(n=328)$ of the participants were female and $31.4 \%(n=150)$ were male. The ages of the participants ranged from 18 to $41(\bar{X}=21.48, \mathrm{SD}=3.76)$. According to the departments, $50 \%(n=239)$ of the participants were students at psychological counseling and guidance, $19.9 \%(n=95)$ were students at primary school mathematics teaching, $7.5 \%(n=36)$ were students at classroom teaching, $7.3 \%(n=35)$ were students at Turkish teaching, $5.9 \%(n=28)$ were students at preschool teaching, 5.2\% $(n=25)$ were students at special education teaching and $4.2 \%$ $(n=20)$ were students at English teaching departments. By grade level, $10.7 \%(n=51)$ of the participants were 1st grade, $39.7 \%(n=190)$ were 2 nd grade, $24.1 \%(n=115)$ were 3 rd grade, $16.9 \%$ were $(n=81) 4$ th grade and $8.6 \%$ were $(n=41)$ graduate students.

\subsection{Data Collection Tools}

\subsubsection{Personal information form}

In the personal information form prepared by the researcher, there are questions asking for the age, gender, department, and class information of the participants.

\subsubsection{Aitken procrastination inventory}

The inventory was developed by Aitken (1982) to determine the tendency of students to postpone academic duties and responsibilities. The scale consists of 19 items on a 5-point Likert scale. Students are asked to rate themselves between 1 (Totally incorrect) and 5 (Totally correct) points for each item. High scores indicate that students have a tendency to procrastinate. The internal consistency coefficient of the scale was reported as $a=.82$ in total. The internal consistency 
coefficient of the scale, which was adapted into Turkish by Balk1s (2006), was reported as $a=.89$ (Balkıs, 2006). The Cronbach Alpha reliability value calculated in this study is $a=.92$.

\subsubsection{Frost multidimensional perfectionism scale}

The scale is a 35-item measurement tool developed by Frost et al. (1990) in order to make a multidimensional evaluation of perfectionism. The scale has a Likert type rating of 1 'strongly disagree' and 5 'strongly agree'. The scale consists of 6 sub-scales: Concern over mistakes, personal standards, parental expectations, parental criticism, doubts about actions, and organization. Evaluation is made according to the total scores of the scale. High score obtained from the scale indicates a higher level of perfectionism. A cut-off point was not calculated in the Turkish sample. The Turkish adaptation of the scale was made by Kağan (2011), and the reliability coefficient was found to be .91. The Cronbach Alpha reliability value calculated in this study is .89 .

\subsubsection{The self-compassion scale}

The scale developed by Neff (2003b) consists of 26 items and six sub-dimensions. The answers given to the items in the five-point Likert-type scale are scored as "Almost never=1" and "Almost always $=5$ ". The Turkish adaptation of the scale was made by Deniz et al. (2008). The Turkish version of the scale has a single factor structure and the total score could be used to represent overall self-compassion levels. In addition, in the Turkish version of the scale, which had 26 items in its original form, the items with a total item correlation of less than .30 were removed and the final version of the scale was determined as including 24 items. The internal consistency coefficient of the Turkish form was calculated as .89 and the test-retest correlation was calculated as .83 . The Cronbach Alpha reliability value calculated in this study is .94.

\subsection{Data Collection and Analysis}

Before testing the model, the collected data skewness and kurtosis values were examined. It was observed that the skewness values varied between -.03 and -1.23 , and the kurtosis values ranged between -.03 and 1.14, and therefore the values were within the normal distribution limits. In the structural equation modeling used in testing the model determined in the research, the Maximum Likelihood method was used as the estimation method together with the covariance matrix while evaluating the relations between the variables. The data were analyzed with IBM SPSS 25, IBM SPSS AMOS 25 and Lisrel 8.8 package programs.

\section{Results}

A two-stage approach, which is widely used in structural equation modeling studies, was performed in this study. In the first stage, the measurement model was created and tested, and the structural model test was carried out by determining that the goodness-of-fit values met the acceptance criteria. The findings regarding the measurement model and the structural model are given below.

\subsection{Findings Related to the Measurement Model}

When the conceptual model created to be tested within the scope of the research was examined (see Figure 1), there are three latent variables: Perfectionism, self-compassion, and academic procrastination. Among these variables, the sub-factors of the frost multidimensional perfectionism scale, which was used to measure perfectionism, are considered as two superordinate factors as adaptive and maladaptive perfectionism (Stoeber \& Gaudreau, 2017). In this study, since maladaptive perfectionism was measured, the total scores of the factors concern over mistakes and doubts about actions, which measure maladaptive perfectionism, were used.

Because the self-compassion scale used to measure the latent variable of "self-compassion" in the model had a single factor structure, three parcels obtained by item parcellation method were assigned as the observed variable. Similarly, since the Aitken Procrastination Inventory, which was used to measure the latent variable of "academic procrastination", had a one-dimensional 
structure, three parcels obtained by the item parcelling method were used as the observed variable. Correlations between the observed variables in the structural model are also presented in Table 1.

Table 1

Pearson Correlation Analysis Results for the Relationships Between Observed Variables in the Structural Model

\begin{tabular}{lllllllll}
\hline & 1 & 2 & 3 & 4 & 5 & 6 & 7 & 8 \\
\hline 1.SCP1 & 1 & & & & & & & \\
2.SCP2 & $.775^{* *}$ & 1 & & & & & & \\
3.SCP3 & $.751^{* *}$ & $.766^{* *}$ & 1 & & & & \\
4. APP1 & $-.424^{* *}$ & $-.466^{* *}$ & $-.373^{* *}$ & 1 & & & \\
5.APP2 & $-.432^{* *}$ & $-.498^{* *}$ & $-.360^{* *}$ & $.833^{* *}$ & 1 & & \\
6.APP3 & $-.380^{* *}$ & $-.484^{* *}$ & $-.349^{* *}$ & $.803^{* *}$ & $.818^{* *}$ & 1 & & \\
7.COM & $-.222^{* *}$ & $-.294^{* *}$ & $-.233^{* *}$ & $.558^{* *}$ & $.514^{* *}$ & $.515^{* *}$ & 1 & \\
$8 . D A A$ & $-.297^{* *}$ & $-.371^{* *}$ & $-.297^{* *}$ & $.537^{* *}$ & $.539^{* *}$ & $.532^{* *}$ & $.628^{* *}$ & 1 \\
\hline
\end{tabular}

${ }^{*}$ Note. ${ }^{*} p<.01$, COM: Frost Multidimensional Perfectionism Scale Concern Over Mistakes subscale total score; DAA: Frost Multidimensional Perfectionism Scale Doubts About Actions subscale total score; SCP1-3: Three parcels from Self-Compassion Scale items; APP1-3: Three parcels from Aitken Procrastination Inventory items.

When the correlation coefficients presented in Table 1 are examined, it is seen that all values are statistically significant.

\subsection{Testing the Measurement Model}

Because the two-stage approach was preferred in the research, the measurement model was created and tested using confirmatory factor analysis before the structural model was tested. The standardized path coefficients for the measurement model are given in Figure 2.

Figure 2

Standardized Path Coefficients for Measurement Model

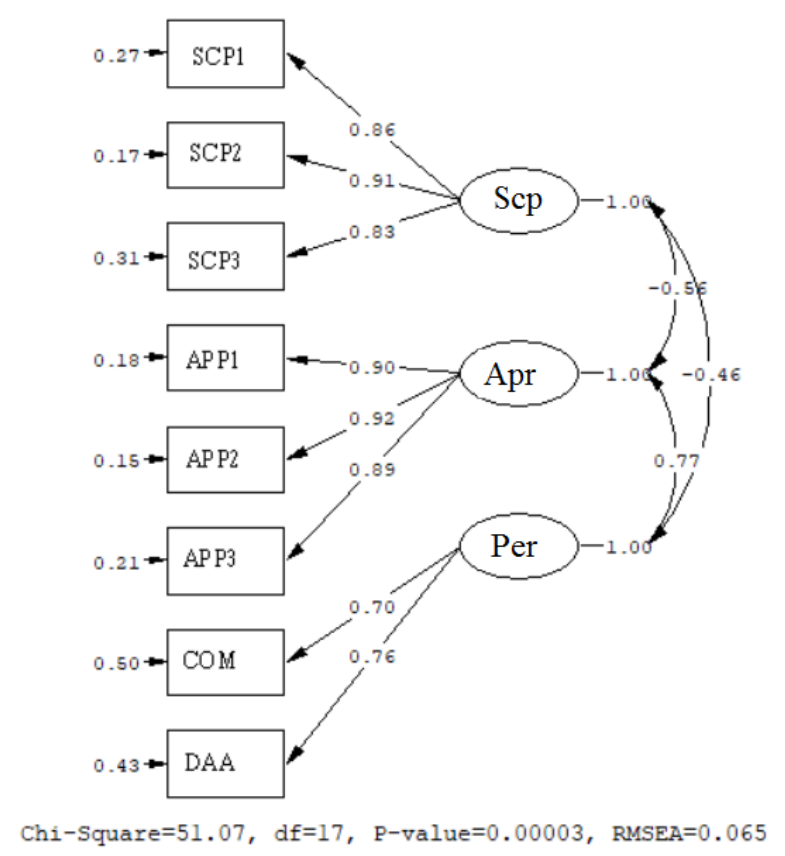

*Note. Scp: Self-Compassion; Apr: Academic Procrastination; Per: Perfectionism; COM: Frost Multidimensional Perfectionism Scale Concern Over Mistakes subscale total score; DAA: Frost Multidimensional Perfectionism Scale Doubts About Actions subscale total score; SCP1-3: Three parcels from Self-Compassion Scale items; APP1-3: Three parcels from Aitken Procrastination Inventory items. 
The standardized path coefficients for the measurement model in Figure 2 showed that examined, the relationships between latent variables and observed variables were high, and the error variances of the observed variables were low. This finding showed that the measurement model was compatible and acceptable with the data collected in the study. The acceptance criteria of various goodness-of-fit indices commonly used in determining model fit and the goodness-of-fit values obtained in this study are presented in Table 2 below.

Table 2

Goodness of Fit Indices Regarding the Measurement Model

\begin{tabular}{lcc}
\hline Goodness of Fit Indices & $\begin{array}{c}\text { Acceptance } \\
\text { Criteria }\end{array}$ & $\begin{array}{c}\text { Goodness of Fit Index } \\
\text { Values of Measurement } \\
\text { Model }\end{array}$ \\
\hline$\chi^{2} / \mathrm{df}$ & $\leq 3$ & 3 \\
Root Mean Square Error of Approximation (RMSEA) & $\leq .08$ & .07 \\
90 Percent Confidence Interval for RMSEA & $\leq .08$ & $(.05 ; .08)$ \\
Normed Fit Index (NFI) & $\geq .90$ & .99 \\
Non-Normed Fit Index (NNFI) & $\geq .90$ & .98 \\
Comparative Fit Index (CFI) & $\geq .90$ & .99 \\
Incremental Fit Index (IFI) & $\geq .90$ & .99 \\
Standardized RMR & $\leq .08$ & .03 \\
Goodness-of-fit Index (GFI) & $\geq .90$ & .97 \\
Adjusted Goodness-of-fit Index (AGFI) & $\geq .90$ & .94 \\
\hline
\end{tabular}

As can be seen from the Table 2, all values meet the acceptance criteria considering the goodness-of-fit statistics of the measurement model. According to these findings, the measurement model was confirmed.

The correlation values of the latent variables in the measurement model are repoted in Table 3.

Table 3

Correlations Regarding the Latent Variables in the Structural Model

\begin{tabular}{lccc}
\hline Latent Variable & 1 & 2 & 3 \\
\hline 1. Self-Compassion & - & & \\
2. Academic Procrastination & $-.56^{*}$ & - & \\
3. Perfectionism & $-.46^{*}$ & $.77^{*}$ & - \\
\hline Note. ${ }^{*} p<.01$ & &
\end{tabular}

According to the correlation values in Table 3, there is a positive relationship between perfectionism and academic procrastination $(r=.77, \mathrm{p}<.01)$, a negative relationship between perfectionism and self-compassion $(r=-.46, \mathrm{p}<.01)$, and academic procrastination. It is seen that there are negative $(r=-.56, \mathrm{p}<.01)$ significant relationships between academic procrastination and self-compassion.

\subsection{Findings Related to the Structural Model}

In the first stage of the two-stage structural equation study adopted in the research, a very good measurement model was created in terms of goodness-of-fit statistics. In the second stage, a structural model that explains the structural relationships between the latent variables in the model was created and tested. The standardized path coefficients of the structural model are given in Figure 3. 
Figure 3

Standardized Path Coefficients for Structural Model

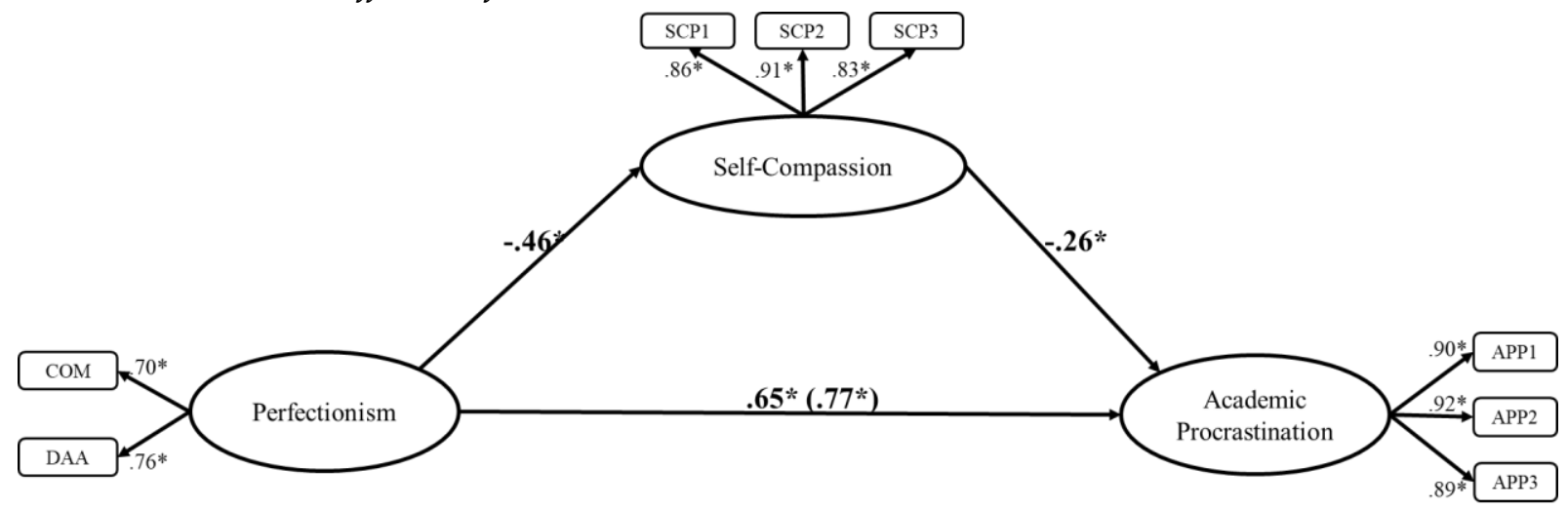

${ }^{*}$ Note. ${ }^{*} \mathrm{p}<.01$, COM: Frost multidimensional perfectionism scale concern over mistakes subscale total score; DAA: Frost multidimensional perfectionism scale doubts about actions subscale total score; SCP1-3: Three parcels from selfcompassion scale items; APP1-3: Three parcels from Aitken procrastination Inventory items.

The standardized path coefficients for the structural model presented in Figure 3 shows that perfectionism has a negative predictive impact on self-compassion $(\beta=-.46, p<.05)$ and a positive predictive impact on academic procrastination $(\beta=.65, p<.05)$, while the predictive effect of selfcompassion on academic procrastination is negative $(\beta=-.26, \mathrm{p}<.05)$.

When the structural equations in the Lisrel output file are examined, it is seen that the structural equation related to academic procrastination was as follows:

$$
\text { Academic procrastination }=-0.26 * \text { Self }- \text { compassion }+0.65 * \text { Perfectionism }
$$

Errorvar. $=0.36, R^{2}=0.64$. According to this finding, perfectionism and self-compassion variables together explain $64 \%$ of the variance in academic procrastination. Goodness-of-fit values for the structural model shown in Figure 3 are presented in Table 4.

Table 4

Goodness of Fit Indices Regarding the Structural Model

\begin{tabular}{lcc}
\hline Goodness of Fit Indices & $\begin{array}{c}\text { Acceptance } \\
\text { Criteria }\end{array}$ & $\begin{array}{c}\text { Goodness of Fit Index } \\
\text { Values of Structural } \\
\text { Model }\end{array}$ \\
\hline$\chi^{2} / \mathrm{df}$ & $\leq 3$ & 3 \\
Root Mean Square Error of Approximation (RMSEA) & $\leq .08$ & .07 \\
90 Percent Confidence Interval for RMSEA & $\leq .08$ & $(.05 ; .08)$ \\
Normed Fit Index (NFI) & $\geq .90$ & .99 \\
Non-Normed Fit Index (NNFI) & $\geq .90$ & .98 \\
Comparative Fit Index (CFI) & $\geq .90$ & .99 \\
Incremental Fit Index (IFI) & $\geq .90$ & .99 \\
Standardized RMR & $\leq .08$ & .03 \\
Goodness-of-fit Index (GFI) & $\geq .90$ & .97 \\
Adjusted Goodness-of-fit Index (AGFI) & $\geq .90$ & .94 \\
\hline
\end{tabular}

The goodness-of-fit values in Table 4 show that all values of the model meet the acceptance criteria. According to these findings, the structural model was validated.

\subsection{Significance of Indirect Effects for the Structural Model}

The significance level of the indirect effects in the model was tested with the Bootstrap method. The results regarding the significance of indirect effects in the structural model are given in Table 5. 
Table 5

Bootstrap Analysis Results for the Significance of Indirect Effects

\begin{tabular}{lcccc}
\hline Independent Variable & Mediator Variable & $\begin{array}{c}\text { Dependent } \\
\text { Variable }\end{array}$ & Path Coefficient $(\beta)$ & $\% 95$ CI-Bias Corrected \\
\hline Perfectionism & Self-compassion & $\begin{array}{c}\text { Academic } \\
\text { Procrastination }\end{array}$ & $.65^{*}\left(.77^{*}\right)$ & {$[.082, .157]$} \\
\hline
\end{tabular}

${ }^{*}$ Note. Bootstrap was conducted on a sample of 5000 observations. $\beta=$ Standardized. ${ }^{*} p<.01$.

As can be seen in Table 5, when the mediator variable had no effect in the model, the path coefficient from perfectionism to academic procrastination was $\beta=.77$, while this coefficient decreased to $\beta=.65$ when the mediating variable came into play. As a result of the bootstrap analysis, it is seen that the indirect effects found in the model are statistically significant at the .05 level. According to this finding, self-compassion had a partial mediating role in the relationship between perfectionism and academic procrastination, and the research hypothesis was confirmed.

\section{Discussion and Conclusion}

The structural equation modeling method was used to assess the mediating role of self-compassion in the relationship between perfectionism and academic procrastination in teacher candidates in this study. The path from perfectionism to academic procrastination was statistically significant and there was a strong positive link between the variables when the paths in the mediation model built within the scope of the research hypothesis were evaluated. Therefore, as perfectionism increases, academic procrastination behaviors increase in teacher candidates. According to Fiore (1989), people with high levels of perfectionism perceive their failure as "failure of themselves as human beings", not as "failure of the task". For this reason, students who set high standards for themselves, do not tolerate failure and are seriously worried about the possibility of failure (Acar, 2021), resort to procrastination behavior more in their academic duties and responsibilities (Fiore, 1989). Perfectionists' high fear of making mistakes, uncertainty about when a task will be completed, and unwillingness to perform the activity can all contribute to procrastination. Thus, procrastination can function as an escape mechanism that avoids the risk of encountering less than perfect performance. The finding of a positive relationship between perfectionism and procrastination obtained in this study is in line with the results of various studies in the related literature (Bulut, 2014; Burns, 1980; Frost et al., 1990; Hamachek, 1978; Sarığlu, 2011; Shafran \& Mansell, 2001; Sorotzkin, 1985; Stoeber \& Stoeber, 2009). In addition, in a study conducted by Bulut and Ocak (2017) in which only the factors affecting the academic procrastination behaviors of teacher candidates were examined, it was found that academic procrastination behavior was partially caused by perfectionism.

In the mediation model tested in the research, the path from perfectionism to self-compassion was found to be negative and statistically significant. According to this finding, as the level of perfectionism increases, self-compassion decreases in teacher candidates. This finding obtained in the study is in line with the relevant literature. For example, in the study conducted by Stoeber et al. (2020) examining the mediating role of self-compassion in the relationship between perfectionism and subjective well-being, it was found that self-oriented and socially prescribed perfectionism was negatively related to self-compassion. In another study, it was found that there is a negative relationship between self-compassion and perfectionism (Çarkit \& Yalçın 2021).

Perfectionism is the setting of unrealistic standards over one's performance and the inability to tolerate the thought of not reaching these standards (Frost et al., 1990). Individuals with a high level of perfectionism adopt an overly critical attitude towards themselves when they cannot reach the high standards they set (Hewitt \& Flett, 1991). This overly judgmental and rigid attitude of the individual towards himself may prevent him from approaching himself with compassion and acceptance, and may cause a decrease in the level of self-compassion.

In the mediation model tested in the study, the relationship between self-compassion and academic procrastination was found to be negative. According to this finding, an increase in 
individuals' self-compassion levels results a decrease in their procrastination behaviors. One of the most important reasons behind procrastination is the fear of failure (Fiore, 1989; Solomon \& Rothblum, 1984). An individual who has a belief that his/her own worth depends on his/her performance, tends to procrastinate when he/she feels the possibility of failure, in order not to face this negative emotion (Burka \& Yuen, 2008). However, individuals with high levels of selfcompassion accept that making mistakes is an inevitable part of human nature and that it is possible to fail sometimes (Neff, 2003a). In this context, people who face failure and learn from it are less likely to resort to procrastination, which acts as an irrational coping mechanism.

In the study, the mediating role of self-compassion in the relationship between perfectionism and academic procrastination was tested according to the confidence intervals based on the bootstrap technique, and the indirect effect was found to be significant. According to this finding, self-compassion plays a partial mediating role in the relationship between perfectionism and academic procrastination. This finding shows that the increase in perfectionism results a decrease in self-compassion, while low self-compassion increases academic procrastination. When this finding obtained in the study was compared with the relevant literature, no study was found that examined the mediating role of self-compassion between perfectionism and academic procrastination. Looking at other studies examining the mediating role of self-compassion, Stoeber et al. (2020) found that self-compassion has a full mediating role in the relationship between perfectionism and subjective well-being. In the study conducted by Şahin (2021), in which the mediating role of self-compassion in the relationship between perfectionism dimensions and life satisfaction in university students was examined, it was found that self-compassion fully mediated the relationship between maladaptive perfectionism and life satisfaction. In another study examining the mediating role of self-compassion in the relationship between anxiety and procrastination, it was found that isolation, self-judgment and hyper-identification, which are subdimensions of self-compassion, were associated with procrastination, and that self-judgment and over-identification had full mediation roles in the relationship between anxiety and procrastination (Einabad et al., 2017)

When the results obtained in the study were evaluated in general, it was found that the variables of perfectionism and self-compassion together explained a large part of the variance in academic procrastination. This finding is very important because academic procrastination is a variable that produces serious negative results for students in terms of both its frequency and consequences. In a study conducted by Solomon and Rothblum (1984), it was found that $46 \%$ of students postponed writing term papers, $27.6 \%$ delaying studying for exams, and $30.1 \%$ doing weekly homework. In addition, $23.7 \%$ of the students stated that the procrastination behavior they experienced while preparing a term paper, $21.2 \%$ while studying for the exams and $23.7 \%$ while doing their weekly homework was a major problem for them. Another important finding obtained in the study is that $65 \%$ of the students stated that they were uncomfortable with the procrastination behavior they experienced while preparing term papers, $62.2 \%$ were uncomfortable while studying for exams and $55.1 \%$ were uncomfortable while doing their weekly homework (Solomon \& Rothblum, 1984). There is a relationship between academic procrastination and low student grades (Beswick et al., 1988; Fritzsche et al., 2003; Klassen et al., 2008; Moon \& Illingworth, 2005; Steel et al., 2001; Tice \& Baumeister, 1997; van Eerde, 2003); mental and physical stress, sleep-related problems, fatigue and illness (Grunschel et al., 2013a; Patrzek et al., 2012; Rothblum et al., 1986; Tice \& Baumeister, 1997); negative emotional outcomes such as anxiety, anger, shame, dissatisfaction, sadness, feeling under pressure, and guilt (Grunschel et al., 2013a; Patrzek et al., 2012; Pychyl et al., 2000; Rothblum et al., 1986; Tice \& Baumeister, 1997).

Considering the prevalence of academic procrastination behavior and its systematic increase from first year to senior year at university (Semb et al., 1979 as cited in Solomon \& Rothblum, 1984), it is extremely important to prevent the negative consequences of this situation for teacher candidates in many respects. For this purpose, first of all, the variables related to procrastination should be determined and controlled. In this context, it is important to reduce the level of 
perfectionism, which is shown as one of the main reasons for procrastination (Burns, 1980; Hamachek, 1978; Shafran \& Mansell, 2001; Sorotzkin, 1985; Stoeber \& Stoeber, 2009), and to carry out activities that increase self-compassion, which has a significant role in reducing both perfectionism and academic procrastination.

\subsection{Recommendations}

Finally, the following recommendations are made based on the results of the study:

$>$ Considering the mediating role of self-compassion in reducing the negative effect of perfectionism on academic procrastination, the development of psycho-educational programs that will support pre-service teachers' self-compassion may be beneficial in reducing both the level of academic procrastination and the negative effect of perfectionism on procrastination.

$>$ Psychological counseling should be provided to prospective teachers whose mental health is adversely affected as a result of academic procrastination.

- The preparation of psycho-educational programs in order to change the fear of failure in perfectionist individuals and their irrational beliefs that their own values are as much as their performance and making this program a part of mental health services at the university can have important contributions to teacher candidates.

> This research was carried out only from a limited sample of pre-service teachers and data collected with self-report scales. Enriching the model tested in the study with students from different faculties and self-report scales as well as observation and interview data may help to better understand the relationships between variables.

In this study, it was found that self-compassion partially mediated the relationship between perfectionism and academic procrastination. Therefore, raising self-compassion alone may not be sufficient to eliminate the negative effects of perfectionism on academic procrastination. For this reason, it is important to include skill-based studies using cognitive, motivational and behavioral strategies that reduce perfectionism.

\section{References}

Acar, F. (2021, May). What are the reasons behind the achievement of successful university students? [Paper presentation]. International Congress of Pedagogical Research, Malaysia.

Aitken, M. E. (1982). A personality profile of the college student procrastinator (Publication No. 31452456) [Unpublished Doctoral dissertation]. University of Pittsburgh, USA.

Aydoğan, D., \& Özbay, Y. (2012). Explanation of academic procrastination from self-esteem, state anxiety, self-efficacy. Pegem Journal of Education and Instruction, 2(3), 1-9.

Balk1s, M. (2006). The relationships between student teachers' procrastination behaviors and thinking styles and decision making style (Publication No. 189853) [Unpublished Doctoral dissertation]. Dokuz Eylül University, Izmir, Turkey.

Balkıs, M., \& Duru, E. (2010). The role of general and performance self-esteem in relation academic procrastination and academic achievement. Pamukkale University Journal of Education, 27(27), 159-1.

Beck, B. L., Koons, S. R., \& Milgrim, D. L. (2000). Correlates and consequences of behavioral procrastination: The effects of academic procrastination, self-consciousness, self-esteem and self-handicapping. Journal of Social Behavior \& Personality, 15(5), 3-13.

Beswick, G., Rothblum, E. D., \& Mann, L. (1988). Psychological antecedents of student procrastination. Australian Psychologist, 23, 207-217. https://doi.org/10.1080/00050068808255605

Blatt, S. J., D'Afflitti, J. P., \& Quinlan, D. M. (1976). Experiences of depression in normal young adults. Journal of Abnormal Psychology, 85, 383-389. https://doi.org/10.1037/0021-843X.85.4.383

Brown, J. D. (1998). The self. McGraw-Hill

Brown, L., Bryant, C., Brown, V., Bei, B., \& Judd, F. (2016). Self-compassion, attitudes to ageing and indicators of health and well-being among midlife women. Aging \& Mental Health, 20(10), 1035-1043. https://doi.org/10.1080/13607863.2015.1060946 
Bulut, R., \&. Ocak. G. (2017). The reasons affecting academic procrastination behaviors of prospective teachers. E-International Journal of Educational Research, 8(2), 75-90

Burka, J. B., \& Yuen, L. M. (2008). Procrastination: Why you do it, what to do about it now. Da Capo Press.

Burns, D. D. (1980). The perfectionist's script for self-defeat. Psychology Today, 14(6), 34-51.

Coopersmith, S. (1967). The antecedents of self-esteem. W. H. Freeman and Company.

Çarkıt, E. \& Yalçın, S. B. (2021). Self compassion as predictor of positive-negative affect and perfectionism in university students. The Journal of Turkish Educational Sciences, 19(1), 383-402. https://doi.org/10.37217/tebd.697249

Çuhadaroğlu, F. (1986). Self-esteem in adolescents [Unpublished Master's thesis]. Hacettepe University, Ankara.

Deniz, M. E., Kesici, Ş., \& Sümer, A. S. (2008). The validity and reliability of the Turkish version of the self$\begin{array}{llll}\text { compassion scale. Social Behavior and Personality, 36(9), 1151-1160. } & \text {. }\end{array}$ https://doi.org/10.2224/sbp.2008.36.9.1151

Dumont, M., \& Provost, M. A. (1999). Resilience in adolescents: Protective role of social support, coping strategies, self-esteem, and social activities on experience of stress and depression. Journal of Youth and Adolescence, 28(3), 343-363. https://doi.org/10.1023/A:1021637011732

Erözkan, A. (2008). Perfectionism tendencies and depression levels of university students. Cypriot Journal of Educational Sciences, 3(2),76-88.

Ferrari, J. R. (1994). Dysfunctional procrastination and its relationship with self-esteem, interpersonal dependency, and self-defeating behaviors. Personality and Individual Differences, 17(5), 673-679. https://doi.org/10.1016/0191-8869(94)90140-6

Ferrari, J. R., \& Tibbett, T. P. (2017). Procrastination. In V. Zeigler-Hill \& T. K. Shackelford (Eds.), Encyclopedia of personality and individual differences (pp. 1-8). Springer.

Ferrari, J. R., Doroszko, E., \& Joseph, N. (2005). Exploring procrastination in corporate settings: Sex, status, and settings for arousal and avoidance types. Individual Differences Research, 3(2), 140-149.

Ferrari, J. R., Johnson, J. L., \& McCown, W. G. (1995). Procrastination and task avoidance: Theory, research, and treatment. Plenum Press.

Fiore, N. (1989). The now habit: A strategic program for overcoming procrastination and enjoying guilt-free play. Penguin Putnam.

Flett, G. L., \& Hewitt, P. L. (2002). Perfectionism and maladjustment: An overview of theoretical, definitional, and treatment issues. In G. L. Flett \& P. L. Hewitt (Eds.), Perfectionism: Theory, research, and treatment (pp. 5-31). American Psychological Association. https://doi.org/10.1037/10458-001

Flett, G. L., \& Hewitt, P. L. (2006). Positive versus negative perfectionism in psychopathology: A comment on Slade and Owens's dual process model. Behavior Modification, 30(4), 472-495. https://doi.org/10.1177/0145445506288026

Flett, G. L., Hewitt, P. L., Besser, A., Su, C., Vaillancourt, T., Boucher, D., Munro, Y., Davidson, L. A., \& Gale, O. (2016). The child-adolescent perfectionism scale: Development, psychometric properties, and associations with stress, distress, and psychiatric symptoms. Journal of Psychoeducational Assessment, 34(7), 634-652. https://doi.org/10.1177/0734282916651381

Flett, G. L., Hewitt, P. L., Blankstein, K. R., \& Mosher, S. W. (1991). Perfectionism, self-actualization, and personal adjustment. Journal of Social Behavior \& Personality, 6(5), 147-160.

Fritzsche, B. A., Young, B. R., \& Hickson, K. C. (2003). Individual differences in academic procrastination tendency and writing success. Personality and Individual Differences, 35, 1549-1557. https://doi.org/10.1016/S0191-8869(02)00369-0

Frost, R. O., Marten, P., Lahart, C., \& Rosenblate, R. (1990). The dimensions of perfectionism. Cognitive Therapy and Research, 14(5), 449-468. https:// doi.org/10.1007/BF01172967

Gilbert, P. (2005). Introduction and outline. In P. Gilbert (Ed.), Compassion: Conceptualisations, research and use in psychotherapy (pp. 1-6). Routledge.

Gilbert, P., \& Irons, C. (2005). Therapies for shame and self-attacking, using cognitive, behavioural, emotionalimagery and compassionate mind training. In P. Gilbert (Ed.), Compassion: Conceptualisations, research and use in psychotherapy (pp. 263-325). Routledge.

Greenberg J., Pyszczynski T., \& Solomon S. (1986) The Causes and Consequences of a Need for Self-Esteem: A Terror Management Theory. In: Baumeister R.F. (eds) Public Self and Private Self. Springer.

Grunschel, C., Patrzek, J., \& Fries, S. (2013b). Exploring different types of academic delayers: A latent profile analysis. Learning and Individual Differences, 23, 225-233. https://doi.org/10.1016/j.lindif.2012.09.014 
Guo, M., Yin, X., Wang, C., Nie, L., \& Wang, G. (2019). Emotional intelligence a academic procrastination among junior college nursing students. Journal of Advanced Nursing, 75(11), 27102718. https://doi.org/10.1111/jan.14101

Hamachek, D. E. (1978). Psychodynamics of normal and neurotic perfectionism. Psychology: A Journal of Human Behavior, 15(1), 27-33.

Hayes, A. F. (2009). Beyond Baron and Kenny: Statistical mediation analysis in the new millennium. Communication Monographs, 76(4), 408-420. https:// doi.org/10.1080/03637750903310360

Hewitt, P. L., \& Flett, G. L. (1991). Perfectionism in the self and social contexts: Conceptualization, assessment, and association with psychopathology. Journal of Personality and Social Psychology, 60(3), 456470. https:// doi.org/10.1037/0022-3514.60.3.456

Hibbard, D. R., \& Walton, G. E. (2014). Exploring the development of perfectionism: The influence of parenting style and gender. Social Behavior and Personality: An International Journal, 42(2), 269278. https://doi.org/10.2224/sbp.2014.42.2.269

Hollander, M. H. (1965). Perfectionism. Comprehensive Psychiatry, 6, 94-103.

Kabat-Zinn, J. (2003). Mindfulness-based stress reduction (MBSR). Constructivism in the Human Sciences, 8(2), 73-83.

Kağan, M. (2011). Psychometric properties of the Turkish version of the Frost Multidimensional Perfectionism Scale. Anatolian Journal of Psychiatry, 12(3), 192-197.

Kawamura, K. Y., Frost, R. O., \& Harmatz, M. G. (2002). The relationship of perceived parenting styles to perfectionism. Personality and Individual Differences, 32(2), 317-327. https://doi.org/10.1016/s01918869(01)00026-5

Klassen, R. M., Krawchuk, L. L., \& Rajani, S. (2008). Academic procrastination of undergraduates: Low selfefficacy to self-regulate predicts higher levels of procrastination. Contemporary Educational Psychology, 33, 915-931. https://doi.org/10.1016/j.cedpsych.2007.07.001

Kline, R. B. (1998). Principles and practice of structural equation modeling. The Guilford Press.

Kljajic, K., Gaudreau, P., \& Franche, V. (2017). An investigation of the $2 \times 2$ model of perfectionism with burnout, engagement, self-regulation, and academic achievement. Learning and Individual Differences, 57, 103-113. https:// doi.org/10.1016/j.lindif.2017.06.004

Lay, C. H. (1986). At last, my research article on procrastination. Journal of Research in Personality, 20, 474-495. https://doi.org/10.1016/0092-6566(86)90127-3

Leary, M. R., Tate, E. B., Adams, C. E., Batts Allen, A., \& Hancock, J. (2007). Self-compassion and reactions to unpleasant self-relevant events: the implications of treating oneself kindly. Journal of Personality and Social Psychology, 92(5), 887-904. https:// doi.org/10.1037/0022-3514.92.5.887

Lee, E. (2005). The Relationship of Motivation and Flow Experience to Academic Procrastination in University Students. The Journal of Genetic Psychology: Research and Theory on Human Development, 166(1), 5-14. https://doi.org/10.3200/GNTP.166.1.5-15

MacBeth, A., \& Gumley, A. (2012). Exploring compassion: a meta-analysis of the association between selfcompassion and psychopathology. Clinical Psychology Review, 32(6), 545-552. https:// doi.org/10.1016/j.cpr.2012.06.003

Moon, S. M., \& Illingworth, A. J. (2005). Exploring the dynamic nature of procrastination: A latent growth curve analysis of academic procrastination. Personality and Individual Differences, 38, 297-309. https:/ / doi.org/10.1016/j.paid.2004.04.009

Neff, K. D. (2003a). Self-compassion: An alternative conceptualization of a healthy attitude toward oneself. Self and Identity, 2(2), 85-101. https:/ / doi.org/10.1080/15298860309032

Neff, K. D. (2003b). The development and validation of a scale to measure self-compassion. Self and Identity, 2(3), 223-250. https:// doi.org/10.1080/15298860309027

Neff, K. D. (2011). Self-compassion, self-esteem, and well-being. Social and Personality Psychology Compass, 5(1), 1-12. https://doi.org/10.1111/j.1751-9004.2010.00330.x

Neff, K. D., Kirkpatrick, K. L., \& Rude, S. S. (2007). Self-compassion and adaptive psychological functioning. Journal of Research in Personality, 41(1), 139-154. https:/ / doi.org/10.1016/j.jpp.2006.03.004

Neff, K., Hsieh, Y., \& Dejitterat, K. (2005). Self-compassion, achievement goals, and coping with academic failure. Self and Identity, 4, 263-287. https:/ / doi.org/10.1080/135765004444000317

Ozer, B. U., Demir, A., \& Harrington, N. (2012). Psychometric properties of frustration discomfort scale in a Turkish sample. Psychological Reports, 111(1), 117-128. https://doi.org/10.2466/08.02.18.PR0.111.4.117128 
Pacht, A. R. (1984). Reflections on perfection. American Psychologist, 39(4), 386390. https://doi.org/10.1037/0003-066X.39.4.386

Patrzek, J., Grunschel, C., \& Fries, S. (2012). Academic procrastination: The perspective of university counsellors. International Journal for the Advancement of Counselling, 34, 185-201. https:// doi.org/10.1007/s10447-012-9150-z

Pychyl, T. A., Lee, J. M., Thibodeau, R., \& Blunt, A. (2000). Five days of emotion: An experience sampling study of undergraduate student procrastination. Journal of Social Behavior \& Personality, 15, 239-254.

Raes, F. (2010). Rumination and worry as mediators of the relationship between self-compassion and depression and anxiety. Personality and Individual Differences, 48, 757-761. https:// doi.org/10.1016/j.paid.2010.01.023

Rosenberg, M. (1965). Rosenberg self-esteem scale (RSE). Acceptance and Commitment Therapy Measures Package, 61(52), 18.

Rothblum, E. D., Solomon, L. J., \& Murakami, J. (1986). Affective, cognitive, and behavioral differences between high and low procrastinators. Journal of Counseling Psychology, 33, 387-394. https://doi.org/10.1037/0022-0167.33.4.387

Sahin, E. E. (2021). Self-compassion as a mediator between perfectionism and life-satisfaction among university students. International Journal of Progressive Education, 17(6), 201-214. https://doi.org/10.29329/ijpe.2021.382.14

Schouwenburg, H. C. (2004). Procrastination in Academic Settings: General Introduction. In H. C. Schouwenburg, C. H. Lay, T. A. Pychyl, \& J. R. Ferrari (Eds.), Counseling the procrastinator in academic settings (pp. 3-17). American Psychological Association. https:// doi.org/10.1037/10808-001

Schumacher, R. E., \& Lomax, R. G. (2004). A beginner's guide to structural equation modelling (2nd ed.). Lawrence Erlbaum Associates.

Shafran, R., \& Mansell, W. (2001). Perfectionism and psychopathology: A review of research and treatment. Clinical Psychology Review, 21(6), 879-906. https://doi.org/10.1016/S0272-7358(00)00072-6

Shapiro, S. L., Astin, J. A., Bishop, S. R., \& Cordova, M. (2005). Mindfulness-based stress reduction for healthcare professionals: Results from a randomized trial. International Journal of Stress Management, 12, 164-176.

Shrout, P. E., \& Bolger, N. (2002). Mediation in experimental and nonexperimental studies: new procedures and recommendations. Psychological Methods, 7(4), 422-445. https://doi.org/10.1037//1082-989x.7.4.422

Sirois, F. M. (2004). Procrastination and intentions to perform health behaviors: The role of self-efficacy and the consideration of future consequences. Personality and Individual Differences, 37(1), 115128. https://doi.org/10.1016/j.paid.2003.08.005

Sirois, F. M. (2016a). Introduction: Conceptualizing the relations of procrastination to health and well-being. In F. M. Sirois \& T. Pychyl (Eds.), Procrastination, Health, and Well-Being (pp.3-20). Elsevier.

Sirois, F. M., \& Pychyl, T. (2013). Procrastination and the priority of short-term mood regulation: consequences for future self. Social and Personality Psychology Compass, 7(2), 115127. https://doi.org/10.1111/spc3.12011

Sirois, F. M., Molnar, D. S., \& Hirsch, J. K. (2017). A meta-analytic and conceptual update on the associations between procrastination and multidimensional perfectionism. European Journal of Personality, 31(2), 137159. https://doi.org/10.1002/per.2098

Solomon, L. J., \& Rothblum, E. D. (1984). Academic procrastination: Frequency and cognitive-behavioral correlates. Journal of Counseling Psychology, 31(4), 503-509. https://doi.org/10.1037/0022-0167.31.4.503

Sorotzkin, B. (1985). The quest for perfection: Avoiding guilt or avoiding shame? Psychotherapy: Theory, Research, Practice, Training, 22(3), 564-571. https://doi.org/10.1037/h0085541

Sowislo, J. F., \& Orth, U. (2013). Does low self-esteem predict depression and anxiety? A meta-analysis of longitudinal studies. Psychological Bulletin, 139(1), 213-240. https://doi.org/10.1037/a0028931

Steel, P., \& Klingsieck, K. B. (2016). Academic procrastination: Psychological antecedents revisited. Australian Psychologist, 51(1), 36-46. https://doi.org/10.1111/ap.12173

Steel, P., Brothen, T., \& Wambach, C. (2001). Procrastination and personality, performance, and mood. Personality and Individual Differences, 30, 95-106. https:/ / doi.org/10.1016/S0191-8869(00)00013-1

Stoeber, J., \& Gaudreau, P. (2017). The advantages of partialling perfectionistic strivings and perfectionistic concerns: Critical issues and recommendations. Personality and Individual Differences, 104, 379-386. https://doi.org/10.1016/j.paid.2016.08.039 
Stoeber, J., \& Stoeber, F. S. (2009). Domains of perfectionism: Prevalence and relationships with perfectionism, gender, age, and satisfaction with life. Personality and Individual Differences, 46(4), 530535. https://doi.org/10.1016/j.paid.2008.12.006

Stoeber, J., Lalova, A. V., \& Lumley, E. J. (2020). Perfectionism, (self-)compassion, and subjective well-being: A mediation model. Personality and Individual Differences, 154, 109708. https://doi.org/10.1016/j.paid.2019.109708

Tice, D. M., \& Baumeister, R. F. (1997). Longitudinal study of procrastination, performance, stress, and health: The costs and benefits of dawdling. Psychological Science, 8, 454-458. https://doi.org/10.1111/j.1467-9280.1997.tb00460.x

van Eerde, W. (2003). A meta-analytically derived nomological network of procrastination. Personality and Individual Differences, 35, 1401-1419. https:// doi.org/10.1016/S0191-8869(02)00358-6

Ying, Y. W. (2009). Contribution of self-compassion to competence and mental health in social work students. Journal of Social Work Education, 45, 309-323. https:// doi.org/10.5175/JSWE.2009.200700072 